\title{
REVISITANDO EL OFICIO DE SOCIÓLOGO: NOTAS SOBRE EL HABITUS DE INVESTIGADOR SOCIAL
}

\section{REVISITING THE CRAFT OF SOCIOLOGY: NOTES ABOUT THE SOCIAL RESEARCHER HABITUS}

Dr. Larry Andrade (larry.andrade@conicet.gov.ar) Sede Andina, Universidad Nacional de Río Negro (Bariloche, Argentina)

\begin{abstract}
This article analyses the impact of research training on the methodological decisions in the social sciences. Based on Bourdieu contributions, the main aim of the article is to think about the conditions in which the social researcher habitus is built. One of the central questions that organises the document is how methodological conceptions guiding research are influenced by the training received by researchers.
\end{abstract}

Key words: habitus, methodology, social sciences, research, training.

\section{Resumen}

En este artículo se revisa el impacto que la formación en investigación tiene sobre los modos en que las decisiones metodológicas son asumidas y, más aún, sobre la propia concepción de metodología con la que se piensa y ejecuta una investigación en ciencias sociales. Precisamente, es desde el interior de este campo y desde la mirada sociológica, que se formulan algunas reflexiones en torno al propio habitus de investigador social, valiéndonos para ello de los aportes de Pierre Bourdieu.

Palabras clave: habitus, metodología, ciencias sociales, investigación, formación.

Cuando se quiere huir del mundo tal como es, se puede ser músico, se puede ser filósofo, se puede ser matemático. Pero ¿cómo huir siendo sociólogo? Hay quienes lo logran. Basta con escribir fórmulas matemáticas, con hacer ejercicios de game-theorie o de simulación con su computadora. Para llegar a ver y decir un poco del mundo tal cual es, hay que aceptar estar siempre en lo complicado, lo confuso, lo impuro, lo vago, etc., e ir de este modo contra la idea común del rigor intelectual (Pierre Bourdieu, entrevistado por Beate Krais, editora de la edición alemana de El Oficio

de Sociólogo) 


\section{Introducción}

En el presente artículo revisaré cómo la teoría de Bourdieu abre a los investigadores en ciencias sociales la posibilidad de pensar (e intervenir) en un escenario constituido por un objeto siempre esquivo y complejo: lo que genéricamente se denomina "lo social". Esta problemática ha sido objeto de reflexiones en otro lugar (Andrade 2006), sin embargo, las potencialidades que el tema habilita están lejos de ser agotadas. Por lo cual, proseguiré reflexionando con el ánimo de aportar en el esfuerzo por responder unos interrogantes que apuntan a la médula de una metodología que no se piense como meramente instrumental, sino que se constituya desde la sensibilidad como actitud que orienta la indagación acerca de diversos aspectos de la subjetividad.

En el sintético esfuerzo y aporte aquí presentado, son importantes dos menciones de reconocidos autores contemporáneos. Las mismas no suponen una crítica a la metodología inspirada en un enfoque cuantitativo, sino más bien quieren ser llamados de alerta a una actitud de investigación que avanza hacia el desmenuzamiento de los fenómenos sociales, olvidando que la ocurrencia aquí y ahora responde al interjuego de fuerzas que provienen simultáneamente de distintos niveles del acontecer social y que son contextuales y producto de una construcción histórica. De un lado, Morin afirmó con relación a la contribución de la estadística a partir del Siglo XIX y comienzos del XX: "el único ideal era el de aislar las variables en juego en la interacción permanente en un sistema, pero nunca el de considerar con precisión las interacciones permanentes del sistema. Así, paradójicamente, los estudios ingenuos, en la superficie de los fenómenos, eran mucho más complejos, es decir, en última instancia, 'científicos', que los pretenciosos estudios cuantitativos sobre estadísticas inmensas, guiadas por pilotos de poco cerebro. Así lo eran, digo con falta de modestia, mis estudios fenoménicos que intentaban aprehender la complejidad de una transformación social multidimensional en una comunidad" (Morin 2000:59).

Por otro lado, Sorokin sostuvo hace algún tiempo: "hay evidencias que prueban que tendemos a producir sociólogos jóvenes con aptitudes de investigación superior, pero con una incapacidad para pensar en términos teóricamente innovadores. Gran parte de nuestra forma actual de entrenamiento, y de nuestro sistema de recompensas a la contribución científica, estimula a los estudiantes a evadir los riesgos del trabajo teórico y buscar la seguridad que proviene de recorrer un camino ya transitado, guiado por los más refinados instrumentos de navegación" (Sorokin 1993:128).

Un aporte que va en el mismo sentido que el aquí pensado es el que reflexiona en torno a que una cosa es estudiar las propiedades del agua y otra, muy distinta, hacerlo con las del hidrógeno y el oxígeno por separado, creyendo que conociendo las de cada uno se conocerán las del agua, ignorando que al juntarse forman algo nuevo, que no estaba en ninguno por separado. Algo similar puede ocurrir con los estudios acometidos desde la selección y análisis de variables individuales, cuando el fenómeno que crean o en el cual participan decisivamente es producto de su interacción y mutuo condicionamiento con otras.

Las afirmaciones de Morin y Sorokin, que guardan diferencias temporales, espaciales y se inscriben en campos de lucha disímiles, coinciden en una crítica a los refinamientos estadísticos que suelen imponerse por sobre la urgente necesidad de pensar los fenómenos, de teorizar acerca de ellos, no para definirlos de una vez por todas, sino para comprender las diversas y complejas articulaciones que llevan a su emergencia y el delicado y central papel que desempeña la metodología en tal posicionamiento. No asumirla meramente centrada en la dimensión instrumental de las técnicas, reduciendo la discusión a la opción por unas u otras, supone pensarla no, justamente, como un conjunto de técnicas y procedimientos, sino como el 
eje de la misma acción de intervención que un sujeto (el investigador) realiza en el marco de una investigación y desde una concepción ontológica de la realidad no siempre explicita pero subyacente y manifiesta, tanto en la visión de lo que vale la pena estudiar como en las definiciones del fenómeno a estudiar, que parte de asumir que hay algo en lo que otros hacen, piensan o dicen que constituye un legítimo interés de investigación (conformándose así en su foco u objeto de investigación).

A los fines de atender los argumentos de quienes dan por cerrada la siempre abierta discusión cualitativocuantitativo (King, Keohane y Verba 2000, por caso) conviene señalar que llevar adelante una investigación orientada por la perspectiva que propone Bourdieu a lo largo de su extensa y rica obra, no significa ser un investigador cualitativo sino, más bien, que tal orientación propone al investigador una actitud distinta frente al mundo social.

Exige pensarlo desde coordenadas diferentes a las que encontramos en manuales de amplia difusión en el grado académico, donde la formación de investigadores sociales se inicia (Sierra Bravo 1988, Festinger y Katz 1993, Galtung 1966, entre otros de una extensa lista). Uno de ellos, Padua (2000:7, cuya primera edición data de 1979), en el primer párrafo del prólogo afirma: "el manual está escrito con el supuesto general de que las ciencias sociales son ciencias empíricas y nomotéticas, cuyo objetivo general es el describir, predecir y explicar" (1). Según señala Piaget, las características fundamentales de las ciencias nomotéticas son: "1. Elaboración o búsqueda de leyes; 2. Utilización de métodos, ya de experimentación estricta, ya de experimentación en sentido amplio, de la observación sistemática acompañada de verificaciones estadísticas; 3. Tendencia a dirigir las investigaciones sobre pocas variables a la vez" (Piaget 1973:46-47). Así pensada, la investigación en las ciencias sociales reduce bastante su capacidad si tuviera por fin comprender las prácticas sociales ejecutadas por los sujetos.

Acordaremos con Sautu (2003) que no se puede criticar la metodología basada en esos manuales. Sin embargo, en tanto sigan siendo utilizados en la formación de investigadores debemos hacerlo. Con referencia a las expresiones aludidas, los aportes del postempirismo (Schuster 2002) han flexibilizado bastante la visión de la ciencia social que orienta ese manual, los cuales no son tomados en cuenta en las sucesivas reediciones.

Importa plantear el punto precedente, especialmente porque a la luz de los importantes desarrollos que ha tenido la práctica metodológica en ciencias sociales, manuales como el de Padua (2000) continúan ofreciendo una visión de la metodología para las ciencias sociales que se referencia en la idea de que existe un método científico único y apropiado para todas las ciencias: una metodología que se parece mucho a la que Hempel (1966) proponía para la ciencia natural. Con ello va, más o menos explícito, una concepción de realidad.

Así conceptualizadas las ciencias sociales, el significado de la palabra "ciencia" quedó en manos de otras, las naturales, y todavía, en buena medida, lo sigue estando: la imagen de un científico se asocia al microscopio no al grabador o al cuaderno de notas de campo -excepto que sea un arqueólogo, al que pocos ubicarían en primera instancia en las ciencias sociales.

Para ser preciso, habría que hablar en vez de mundo social sin más calificativos, de sujetos que habitan un mundo que ellos mismos contribuyen a construir, en general y siguiendo la máxima marxista: "con voluntad pero sin conciencia". La ironía viene al caso porque justamente buena parte del desarrollo que Bourdieu realiza en torno a la idea de habitus, recupera con un peso importante los componentes no-conscientes de 
la acción (inconscientes dirá el autor, entendiendo por tales no reflexivos, ver Bourdieu 1973), aquellos encarnados tan profundamente en las estructuras cognitivas que ejercen dirección sobre las prácticas sin que puedan ser rediscutidos por el sujeto.

Desde ya, que tales estudios no pueden ser posibles en una disciplina sociológica que tenga por meta "describir, explicar y predecir" y donde se hable de datos y/o de hechos sin más aclaraciones (2), sin que conceptos como construcción aparezcan, al menos, con un vínculo tenue con ellos como para indicar que no hay dato a secas y que tales no se captan, sino que lo que se registre como tal, en todo caso, depende de la mirada teórica que sobre el fenómeno tenga el investigador. Porque para estas visiones de la sociedad sólo existe lo dado y lo sometido a leyes, no guardando lugar para cosas tales como "lo inconsciente" y "construcción social", por ejemplo. Aunque se señala algunas veces que "explicar algo ya es comprenderlo", para salvar esa limitación presente en tal concepción de ciencia, se habla de que "las ciencias sociales tienden a la comprensión". Justamente, esto es indicado en una obra reciente (Borsotti 2007), quien fuera uno de los coautores del libro coordinado por Padua (2000) y su expresión se hace eco del impacto que las proposiciones del postempirismo trae consigo a las ciencias sociales.

Muchas de las indicaciones metodológicas concretas que se dan en el Oficio de Sociólogo, según relata Bourdieu, tenían por finalidad marcar una línea que ponga un freno a la expansión de la propuesta de Lazzarsfeld en Francia en particular y Europa en general, con fuerte sesgo hacia la cuantificación y percepción objetiva del mundo social: “[Lazzarsfeld] a través de técnicas interesantes, que era necesario aprender, y que yo había aprendido, imponía otra cosa, es decir, una epistemología implícita de tipo positivista que yo no quería aceptar" (Bourdieu 1997:42).

Lo que importa es darse cuenta que la enorme construcción teórica que Bourdieu desarrolló a lo largo de varias décadas de trabajo ininterrumpido se asienta en una concepción del mundo en la que debe apreciarse nítidamente el interjuego entre estructura social y estructura de pensamiento ( $y$, consecuentemente, de la acción). Considerar esta indicación exige no valorar la práctica de los sujetos a partir de metas pensadas externamente (o, podríamos decir, no solamente) por el investigador, sino desde la propia lógica en la cual el propio ejecutante de la acción valora sus (im)posibilidades y hace aquello que sensatamente asume debe realizar uno-como-él. Importa destacar el ingenioso e impresionante aporte que la conocida como "teoría de las prácticas sociales" ha realizado a los desarrollos teóricos y de investigación en las ciencias sociales y humanas.

Uno de ellos y central, es la consideración del contexto social de referencia para comprender una acción. Un contexto que no es pensado como algo dado sino como algo "vivo" y en constante recreación. Esta sola premisa conlleva como importante la necesidad de encontrar la raíz que guía la práctica que se ejecuta actualmente: porque así como en la planta la raíz está hacia abajo, en las prácticas sociales se extiende hacia atrás, al pasado.

De aquí que el análisis de determinada práctica social (de la comprensión de por qué se hizo lo que se hizo en tal momento) sea inescindible del contexto social de origen, y de la historia: si la recuperación o reconstrucción de la historicidad de la práctica no fuera posible, sería prácticamente imposible comprenderla, puesto que la posibilidad de hacerlo radica en el vínculo que pueda establecerse entre el contexto donde se gestó y el contexto donde se manifiesta (3). La importancia de historizar es claramente destacada por Bourdieu: "hay que rehacer el análisis de la presencia en el mundo, pero historicizándolo, es decir, planteando el problema de la elaboración social de las estructuras o los esquemas de percepción que 
el agente pone en funcionamiento para elaborar el mundo" (1999:193-194). Esa elaboración social, agregamos, está temporalmente situada.

Este ejercicio permite comprender también los desajustes entre los aspectos que fueron atendidos cuando se originó esa práctica, ese modo de ver y hacer, y los que, persistiendo en su orientación, pueden no estarlo en la actualidad. Respecto del contexto, acota el autor con relación a lo que define como principio de la no conciencia: "impone que se construya el sistema de relaciones objetivas en el cual los individuos se hallan insertos y que se expresa mucho más adecuadamente en la economía o en la morfología de los grupos que en las intenciones declaradas de los sujetos" (Bourdieu et. al. 1973:34).

Para hacer un "aterrizaje" de lo hasta aquí expresado, vale la referencia empírica siguiente. En un trabajo de investigación y aplicando conceptualizaciones del esquema bourdieano (Andrade 2005), procuramos comprender el proceso erosivo en una provincia de Argentina a partir de analizar por qué un grupo de productores insistía con la repetición de prácticas que, a todas luces, no daban los resultados esperados. Lo que lo que desde una mirada técnica podía aparecer como una práctica irracional era asumido por los productores como "lo que había que hacer en ese contexto y con esa producción". Era un producto decantado de una tradición productiva, de un modo de ver y hacer las cosas (entre otros posibles) que resultaba necesario revisar, es decir, requeriría cuestionar los fundamentos de la práctica misma. No renovarla con palabras nuevas sin remover la creencia en la efectividad de la misma, inscrita ella en las estructuras más profundas del ser.

Comprender no significa justificar. Esto es, que el trabajo de investigación permita conocer cómo opera un determinado proceso social no supone la aceptación del mismo: luego vendrá la intervención política, técnica, profesional, educativa u otra, con el fin de valorar las posibles direcciones en que el mismo podrá ser reorientado y los modos en que esto podrá ser hecho. Esto es, no alcanza con la toma de conciencia para que la situación mejore, es preciso intervenir activamente para que el cambio ocurra. Comprender la acción supone conocer el habitus a partir del cual la misma se estructura: este es el significado profundo de asumirlos como "estructuras de disposiciones" y también el de pensar a la acción como producto del condicionamiento que la sociedad ejerce sobre cada sujeto a través del tiempo y en diversas instancias: lo que una línea de la sociología denomina “socialización” (Berger y Luckmann 1986).

Una orientación bourdieana de la investigación social es más que la enunciación de sus categorías en un proyecto o informe de investigación, exige la puesta en acto de un modo de pensar lo social y la investigación de lo social desde una postura concordante con tales enunciaciones: lleva consigo el mandato de pensar el mundo social como un espacio dinámico, un flujos de relaciones, espacio de representaciones que generan y/o anulan esas relaciones, de una socialización en la que tales relaciones y representaciones son posibles, de coordenadas y referencias para la vida social y la acción más o menos móviles y también asumir que entre lo "objetivo" y lo "subjetivo" no existe hiato de ningún tipo, sino interjuego y modificación constante y que esa interacción hace que a cada cota de lo social vengan asociadas unas y determinadas formas de pensar, de hacer y de ser, pero que de ninguna manera ni la posición ni esas formas son inmodificables.

En este esfuerzo por anular las discusiones que suelen emergen en términos de dicotomías tales como cuantitativo vs cualitativo, objetivo vs subjetivo (4), etc., también deberemos incluir otra que impacta fuertemente en los investigadores: saber científico-técnico vs saber mundano o cotidiano o práctico. De persistir en sostener la misma nos encontraríamos ante un inevitable e irresoluble problema: en la reflexión 
previa, en el pensamiento científico, suele asumirse que las cosas deben hacerse (o son) de un determinado modo. Sin embargo, en la práctica, los sujetos reales, ajenos a los mandatos y ataduras de la teorización, ejecutan acciones que contradicen este supuesto.

Este es un claro ejemplo de que, sin cambiar el punto de partida, así como la concepción de qué es metodología y el modo de viabilizar la intervención, no podrá lograrse la comprensión de las prácticas que interesa comprender, aun si se mencionan buena parte de las categorías que propone Bourdieu. Con lo cual, importa dejar en claro que el problema que está en juego es uno de concepción del trabajo de investigación, siendo central cómo definimos la idea de realidad y cómo pensamos a los sujetos que la conforman.

Una premisa central en la propuesta bourdieana es la que exige al investigador comprender la trama de relaciones objetivas que hacen del sujeto uno con tales o cuales características, y no contentarse con la interpretación que el propio sujeto hace de la situación, sino buscarla más allá de la propia autoconciencia, en lo que subyace como determinante estructural a la práctica social de los sujetos en un contexto dado.

Siguiendo a Bachelard (1999), Bourdieu sostiene que el hecho se construye, conquista, comprueba (contra la ilusión del saber inmediato, de lo "dado"). Esta posición exige una ruptura que involucra las propias creencias del investigador sobre lo que el objeto es, lo cual reclama un examen y reexamen de lo que Durkheim denomina prenociones o nociones previas acerca de lo que tal o cual fenómeno es, asumiendo que estas son: "teorías que expresan, no los hechos -que no podrían ser agotados con tanta rapidez- sino la idea preconcebida que el autor tenía de ellos antes de la investigación" (Durkheim 1985:15). Conocer es ir más allá de lo que aparece sólidamente establecido y conlleva la necesidad de forzar esa entereza, adentrándose en el entramado de relaciones que fundan su existencia de ese modo y con esas características.

En este esfuerzo por comprender, resulta de primera importancia la vigilancia epistemológica, la que: "subordinando el uso de técnicas y conceptos a un examen sobre las condiciones y los límites de su validez, proscriba la comodidad de una aplicación automática de procedimientos probados que señale que toda operación, no importa cuán rutinaria y repetida sea, debe repensarse a sí misma y en función del caso particular" (Bourdieu et.al. 1973:16).

Atendiendo a señalamientos como los hasta aquí expresados, es que el autor plantea una crítica contundente a la metodología en una acepción restringida del término: como conjunto de reglas, técnicas y procedimientos desde los cuales el objeto es mirado. Según Bourdieu, "la obediencia incondicional a un órganon de reglas lógicas tiende a producir un efecto de 'clausura prematura' al hacer desaparecer, como diría Freud, 'la elasticidad en las definiciones' o, como afirma Carl Hempel, 'la disponibilidad semántica de los conceptos' que constituye una de las condiciones del descubrimiento, por lo menos en ciertas etapas de la historia de una ciencia o el desarrollo de una investigación" (Bourdieu et. al. 1973:21).

En otro texto, Bourdieu es agudamente irónico respecto de esta predominancia de una idea instrumental de metodología que la concibe como "serie de recetas o de preceptos que hay que respetar no para conocer el objeto sino para ser reconocido como conocedor del objeto" (1997:62). Esta crítica mordaz encuentra fundamento en afirmaciones como la siguiente: "construir un objeto no es hacer un 'proyecto de investigación'. Valdría la pena hacer una sociología de los research proposal que los investigadores deben producir, en Estados Unidos, para obtener créditos. Se les pide definir previamente sus objetivos, sus métodos; de probar que lo que hacen es nuevo en relación con los trabajos anteriores, etc. La retórica que 
hay que poner en marcha para suscitar el 'methodological appeal' (...) encierra una epistemología implícita socialmente sancionada. Al punto que, cuando un trabajo de investigación empírica no se presenta según las normas de esta retórica, muchos investigadores (...) tienen la impresión de que no es un trabajo científico" (Bourdieu 1997:52).

Un acto fundacional en el oficio de investigar es la construcción del objeto de investigación (Bourdieu et.al. 1973, 1997), y para ello es imperioso diferenciar cabalmente objeto real (preconstruido por la percepción) de objeto construido (por el investigador). En esta instancia, es menester tomar los propios instrumentos de conocimiento como objeto de estudio, justamente para no dar lugar a que las prenociones se inmiscuyan sigilosamente en nuestra conceptualización del fenómeno a estudiar, también para mantener en consideración la idea de ruptura con el conocimiento ordinario acerca de los fenómenos, el cual se imprime en el acervo de conocimiento como lo que el mundo es, en razón de la decisiva influencia que el mundo social ejerce a tiempo completo sobre los sujetos.

En el párrafo precedente se expresa con meridiana claridad una concepción de lectura crítica del conocimiento cotidiano: no se trata de dejarlo de lado, de descartarlo por a-científico sino, más bien, que el trabajo científico exige buscar y conocer el origen de esas representaciones, el particular momento histórico en que se gestaron para, de ese modo, comprenderlas.

Bourdieu recurre a Pascal para explicar la poderosa presión que el mundo social ejerce sobre los sujetos: "el mundo me comprende, me incluye como una cosa entre las cosas, pero, cosa para las que hay otras cosas, un mundo, comprendo este mundo; y ello, hay que añadir, porque me abarca y me comprende: en efecto, mediante esta inclusión material -a menudo inadvertida o rechazada- y lo que trae como corolario, es decir, la incorporación de las estructuras sociales en forma de estructuras de disposición, de posibilidades objetivas forma de expectativas y anticipaciones, adquiero un conocimiento y un dominio prácticos del espacio circundante" (Bourdieu 1999:173).

Es por esto que la ruptura con las concepciones espontáneas acerca de lo que el objeto es resulta aquí imperiosa y único modo de acceder a la posibilidad de definir un objeto de investigación como una trama de relaciones intencionadas y expresamente construida (por el investigador) y no por la que le son ofrecidas como "naturalmente" constitutivas del fenómeno. A esto alude aquella expresión de que el "el saber científico se conquista contra la ilusión del saber inmediato".

En esta línea argumental, resulta de primera importancia atender al vínculo que se establece entre teoría y lo empírico, entre la conceptualización que existe sobre determinados ámbitos de realidad y el recorte por abstracción que de la misma se realiza con la definición de un problema y la conformación de un objeto de investigación: ni una (la teoría) es inclusiva de toda la realidad ni otros (el problema y el objeto) son producto de la mera ocurrencia del investigador. Aquí se rompe claramente la falsa antinomia de otro par que suele presentarse como antitético. Con el planteo de un problema y la construcción y recorte de un objeto se establece un claro nexo entre teoría y realidad y se destaca con claridad la importancia que la teoría adquiere en la definición de ésta última: su forma, el modo en que la pensamos y nos la apropiamos a través del recorte está en relación directa con la teoría general y/o sustantiva que tomamos como referencia.

Y aquí también radica la importancia de un preciso señalamiento establecido por Bourdieu, el de no ceñirse a lo que la teoría denota, haciendo un uso heurístico de los conceptos, de modo tal que permitan visualizar 
qué otros ámbitos o espacios de concreción o posibilidades de concreción pueden estar subyaciendo y que la teoría actual no esté nombrando: "Ios conceptos o los métodos podrán ser utilizados como instrumentos que, arrancados de su contexto original, se abren a nuevos usos" (1973:15). De aquí la importancia de ser extremadamente cauto en el planteo de hipótesis, con el fin de que las mismas no terminen verificando lo que ya se conoce y no permitan incluir aquello que escapa a la teorización posible en ese momento (Andrade 2007).

\section{Los "otros" tienen habitus... "nosotros" también..!}

La noción de habitus, tan difundida como controvertida, tiene una clara función en la teoría del autor: destacar la presencia constante en todos los sujetos de un saber práctico que conforma un sistema de disposiciones, un saber que agrega un plus a la acción y que la lectura puramente teórica no puede captar. Dar cuenta de él exige asumir a lo social como algo más que un ámbito donde recoger información, es necesario reconocer los contextos y construir desde allí las interpretaciones: "nociones como éstas de habitus, prácticas, etc., tienen por función, entre otras cosas, recordar que hay un saber práctico que tiene su propia lógica, que no es reductible a la del conocimiento teórico; que, en un sentido, los agentes conocen el mundo social mejor que los teóricos. Todo esto recordando también que, bien entendido, ellos no lo conocen verdaderamente y que el trabajo del científico consiste en explicitarlo. Explicitar ese saber práctico, según sus articulaciones propias" (Bourdieu 1997:51).

Cuando el autor define en varios lugares a su enfoque como estructural-constructiva está queriendo indicar que resulta necesario no perder de vista el interjuego entre sujeto y estructura. Ni uno es tan autónomo ni la otra tan rígida: "la noción de habitus intenta posibilitar una teoría materialista del conocimiento que no relegue al idealismo la idea de que cualquier conocimiento, ingenuo o científico, requiere un trabajo de construcción; sin embargo, recalca que este trabajo no tiene nada en común con un trabajo meramente intelectual y que se trata de una actividad de construcción, incluso de reflexión práctica, que las nociones comunes de pensamiento, conciencia y conocimiento nos impiden concebir adecuadamente (...) [la intención teórica de su empleo alienta el deseo de] escapar tanto de la filosofía del sujeto, pero sin sacrificar al agente, como de la filosofía de la estructura, pero sin renunciar a tener en cuenta los efectos que ella ejerce sobre el agente y a través de él" (Bourdieu 1995:83).

O, como lo explica Wacquant, un discípulo y agudo interprete del autor: “objetivismo y subjetivismo (...) necesidad estructural y agenciamiento individual son falsas antinomias (...) Bourdieu convierte (...) paradigmas antagónicos en momentos de una forma de análisis destinada a recapturar la realidad intrínsecamente doble del mundo social. La praxeología social resultante entrelaza un abordaje 'estructuralista' y otro 'constructivista'. Primero, dejamos de lado las representaciones mundanas para construir las estructuras objetivas (espacios de posiciones), la distribución de recursos socialmente eficientes que definen las tensiones externas que se apoyan en las interacciones y representaciones. Segundo, reintroducimos la experiencia inmediata vívida de los agentes con el fin de explicar las categorías de percepción y apreciación (disposiciones) que estructuran su acción desde el interior" (Bourdieu y Wacquant 2005:36-37).

Esta última afirmación resulta no contingente en el análisis sociológico y recuerda (coincidiendo) con la tradición de la fenomenología que, más allá de lo fantaseado o no de las mismas, los sujetos orientan su acción en razón de sus propias construcciones (Wacquant las denomina "representaciones mundanas") acerca de los otros y a partir de las cuales el substrato social puede comenzar a palparse genuinamente. 
Los señalamientos precedentes son apropiados a los fines de iluminar uno de los propósitos que persigue el autor y que importa recuperar en este trabajo: le preocupa destacar la íntima interdependencia entre acción y estructuras mentales con la posición social del sujeto analizado. Sin embargo, importa también dejar claramente establecido cuál es, realmente, el peso de los habitus en las acciones pasadas, actuales y futuras de un sujeto o grupo: además de estructurar las actuales también estructura las por-venir, es decir, se constituye en una verdadera matriz para la acción, una referencia no pensada en la que tantos las acciones como las omisiones encuentran sentido. Esto es lo que lleva al autor a sostener que "en las acciones de los sujetos hay más racionalidad y sistematicidad de la que puede entreverse a simple vista".

Esto es posible, precisamente, porque los habitus son sistemáticos y coherentes, precisamente porque subyace a la acción aquella matriz generadora que la direcciona una y otra vez: "el concepto de habitus tiene como función principal la de hacer hincapié en que nuestras acciones se fundamentan más a menudo en el sentido práctico que en el cálculo racional, o en que (...) el pasado sigue presente y activo en las disposiciones que ha producido; o también en que, en contra de la visión atomística que propone una psicología experimental concreta, empeñada en analizar unas aptitudes o unas actitudes separadas (estéticas, afectivas, cognitivas, etc.), y en contra de la representación (autentificada por Kant) que opone los gustos nobles, llamados 'puros', a los gustos elementales, o alimentarios, los agentes sociales, más a menudo de lo que cabría esperar, tienen unas disposiciones (unos gustos, por ejemplo) más sistemáticos de lo que se podría pensar" (Bourdieu 1999:89).

Esa matriz disposicional no surge en el vacío, sino del influjo que la estructura social ejerce sobre el sujeto en un momento y sociedad determinada: "Ios condicionamientos asociados a una clase particular de condiciones de existencia producen habitus, sistemas de disposiciones duraderas y transferibles, estructuras estructuradas predispuestas a funcionar como estructuras estructurantes, es decir, como principios generadores y organizadores de prácticas y de representaciones que pueden ser objetivamente adaptadas a su meta sin suponer el propósito consciente de ciertos fines ni el dominio expreso de las operaciones necesarias para alcanzarlos, objetivamente 'reguladas' y 'regulares' sin ser para nada el producto de la obediencia a determinadas reglas, y, por todo ello, colectivamente orquestadas sin ser el producto de la acción organizadora de un director de orquesta" (Bourdieu 2005:86).

Conviene ratificar que los habitus (5) son una construcción social e histórica y contextual, es el paso del tiempo (el devenir) lo que tiende a consolidarlos como formas de pensamiento no reflexivas, de conocimiento práctico. Como fue dicho más atrás, existe una estrecha relación entre la estructura social y las estructuras mentales (Bourdieu y Saint Martin 1989), esto es, entre lo que se piensa y el lugar desde donde se lo piensa. En este sentido (y sólo en este) puede sostenerse que lo social internalizado tiene fuerte influencia en las prácticas (cuales quiera sean ellas) ejecutadas actualmente.

Esta es precisamente la importante tarea que Bourdieu entiende que desempeña el habitus: "hay que elaborar una teoría materialista capaz de rescatar del idealismo (...) 'el aspecto activo' del conocimiento práctico que la tradición materialista ha dejado en su poder. Ésta es, precisamente, la función de la noción de habitus, que restituye a la gente un poder generador y unificador, elaborador y clasificador, y le recuerda al mismo tiempo que esa capacidad de elaborar la realidad social, a su vez socialmente elaborada, no es la de un sujeto trascendente, sino la de un cuerpo socializado, que invierte en la práctica de los principios organizadores socialmente elaborados y adquiridos en el decurso de una experiencia social situada y fechada" (Bourdieu 1999:181). 
Justamente, reconocer el interjuego entre estructura y sujeto con la adición de un componente "generador", "creativo", hace de los sujetos seres condicionados pero de ninguna manera absolutamente determinados. También, asume el autor, el habitus tiene una parte que podríamos denominar inestructurada, que hace de él un referente no del todo confiable en determinadas ocasiones, como pueden serlo las de crisis: "el habitus tiene parte ligada con lo impreciso y lo vago. Espontaneidad que se afirma en la confrontación improvisada con situaciones sin cesar renovadas, obedece a una lógica práctica, la de lo impreciso, del más o menos, que define la relación ordinaria con el mundo" (Bourdieu 1996:84; resaltado en el original). Agrega más adelante, en el mismo trabajo: "esta parte de indeterminación, de apertura, de incertidumbre, es lo que hace que no pueda remitirse completamente a él en las situaciones críticas, peligrosas" (Bourdieu 1996:84-85). Sobre este punto señala Wacquant: "es importante enfatizar, finalmente, que las líneas de acción engendradas por el habitus no tienen, y de hecho no pueden tener, la clara regularidad de conducta deducida de un principio normativo o judicial (...) en consecuencia, deberíamos abstenernos de explorar las producciones del habitus en busca de más lógica de la que realmente contienen: 'la lógica de la práctica es ser lógica hasta el punto donde ser lógico cesaría de ser práctico'” (Bourdieu y Wacquant 2005:52).

Al respecto, escribe Bourdieu: "en la mayor parte de las conductas ordinarias, somos guiados por esquemas prácticos, es decir, por 'principios que imponen el orden a la acción' (...) por esquemas informacionales. En suma, todo lo que permite a cada uno de nosotros distinguir las cosas que otros confunden" (1996:85). La referencia aquí está claramente orientada a denotar una función central del habitus: "indica" aquello que resulta de importancia para la práctica que se está ejecutando cotidianamente y que resulta apropiado a los fines de garantizar su reproducción, a la vez que soslaya o directamente ignora aquellos aspectos que no presentan interés para la acción que se ejecuta o en ciernes.

Para decirlo una vez más: en este marco de reflexión y análisis, se impone como premisa metodológica central del análisis interpretativo la consideración del momento histórico en que se gestó un determinado habitus, puesto que la acción de guía en la generación de determinada práctica que ejerce se referencian en aquellos momentos cruciales del surgimiento y consolidación de la actividad en estudio y de los modos de hacer y las visiones a ellos asociadas, incluidas las acciones y omisiones.

La idea de contexto entonces adquiere así un contenido que importa resaltar (una vez más): no puede pensarse como un mero espacio o lugar, sino que es la construcción de un conjunto de relaciones (de diverso tipo) que ha sido realizada ( $y$ son activamente transmitidas) por unos sujetos en un momento particular de su existencia y a cuya reproducción y sostenimiento se orienta la actividad cotidiana.

Justamente en este esfuerzo comprensivo es que debe observarse el contexto actual como el escenario donde un sujeto (el que ejecuta la práctica que importa observar) despliega un libreto (aquello que estamos interesados en comprender), siendo este un conjunto de prácticas producidas y/o aprendidas. El propio libreto del observador indica que debe ( $y$, simultáneamente) que no debe ser tenido en cuenta, siendo esto último un producto decantado de la primera acción: se ve solo lo que resulta de interés (desde una determinada concepción teórica). No se observa "todo" sino todo lo que importa para nuestra conceptualización del fenómeno (Kosik 1967).

Aquí es donde importa explicitar una faceta importante del análisis sociológico: así como aquellos sobre los que vamos a indagar unos determinados aspectos de su vida social (cómo producen, por qué hacen cierta actividad, por qué la hacen de ese modo, cómo visualizan el porvenir, etc.), están conformados según el 
influjo que un contexto social ha ejercido (y ejerce sobre ellos), los que vamos a investigar también somos el producto de un doble proceso de formación: por un lado, y como sujetos socialmente constituidos, también hemos recibido (y recibimos) ese influjo durante nuestros primeros años de vida (y aún después). Esta presión incluye visiones acerca de lo que el mundo social es, el lugar que ocupamos en el mismo, qué es el poder, entre otras.

Por otro lado, como investigadores, hemos sido (y somos) entrenados en una modalidad de visualizar y pensar lo social. Entonces, debe ser objeto de reflexión cuál y cómo ha sido nuestra formación teórica y el entrenamiento recibido en los modos de intervenir prácticamente en eso que genéricamente conocemos como "lo social", puesto que ha sido (y es) ese entrenamiento lo que define el habitus de sociólogo.

Al respecto, Bourdieu afirma que: "aunque la mayoría de los autores han llegado a confundir su teoría particular del sistema social con la teoría del conocimiento de lo social que abrazaban, por lo menos implícitamente en su práctica sociológica, el proyecto epistemológico puede permitirse esta distinción preliminar para vincular autores cuyas oposiciones doctrinarias ocultan el acuerdo epistemológico. Temer que esta empresa conduzca a una amalgama de principios tomados de tradiciones teóricas diferentes o a la constitución de un corpus de fórmulas disociadas de los principios que las fundamentan, implica olvidar que la reconciliación cuyos principios creemos explicitar se opera realmente en el ejercicio auténtico del oficio de sociólogo o, más exactamente, en el 'oficio' del sociólogo, habitus que, en tanto sistema de esquemas más o menos dominados y más o menos transponibles, no es sino la interiorización de los principios de la teoría del conocimiento sociológico. A la tentación que siempre surge de transformar los preceptos del método en recetas de cocina científica o en objetos de laboratorio, sólo puede oponérsele un ejercicio constante de la vigilancia epistemológica" (1973:16).

Si el habitus es un sistema de disposiciones, con relación a la investigación social resulta pertinente atender cómo define el autor a las mismas. A tal fin: "hablar de disposición significa, lisa y llanamente, tomar nota de una predisposición natural de los cuerpos humanos (...) la condicionabilidad como capacidad natural de adquirir capacidades no naturales, arbitrarias. Negar la existencia de disposiciones adquiridas significa, hablando de seres vivos, negar la existencia del aprendizaje como transformación selectiva y duradera del cuerpo que se lleva a cabo por reforzamiento o debilitamiento de las conexiones sinápticas" (Bourdieu 1999:180-181; cursiva mía).

La afirmación que realiza el autor potencia lo indicado más atrás con relación a la socialización primaria (y luego por la secundaria): todo saber hacer se estructura a partir de una selección y acentuación de circunstancias y características que están presentes en un contexto determinado en un cierto tiempo: no son las únicas ni quizás tampoco las decisivas, son las que unos sujetos determinados pueden articular y dotar de una estructura con sentido a partir de lo que sus propias creencias, convicciones, conocimientos previos e intuiciones le permiten.

Hasta hace unos años, cuando se revisaban los programas de formación en investigación en los planes de carreras como sociología, era frecuente encontrar que los libros o manuales que con mayor frecuencia aparecían citados eran algunos como los que referimos al principio de este artículo y otros por el estilo, con una visión procedimental-instrumental de la metodología por sobre una postura de mayor reflexividad y una concepción de lo social compleja, esto es, no como mera agregación de dimensiones susceptibles de ser analizadas en el siempre presente lenguaje de las variables y los métodos estadísticos. Y esto operaba (y tal vez todavía opera) en detrimento de la riqueza y complejidad que ganaba la teorización sobre la social en la 
obra de relevantes sociólogos contemporáneos (el propio Bourdieu, también Giddens, entre otros) y otros que participaron activamente en la delimitación del campo sociológico (Weber, Simmel, por citar algunos).

La concepción de campo como espacio de relaciones de fuerza es otro aspecto clave de la concepción bourdieana de lo social, la cual está también presente en la disputa metodológica al interior de las ciencias sociales: los modos políticamente correctos de abordar y analizar lo social no son ni neutros ni mucho menos consensuados, son el producto de una lucha por imponer visiones legítimas de lo que la metodología para el estudio del mundo social es. Por ello, es menester pensar la sociedad como un espacio de posiciones (de poder) que generan disposiciones que procuran asegurar los lugares ganados. Esas luchas, simbólicas la mayoría de las veces, son producto de asimetrías de capital (social, económico, simbólico, cultural) que cuajan con la ubicación de los sujetos en diferentes posiciones sociales en función de la composición de su capital (una versión de la composición orgánica del capital a la que refería Marx): se puede ser prestigioso y pobre, se puede ser prestigioso y rico pero nunca se podrá ser rico sin suficiente dinero, y este define generalmente la posición del sujeto en la sociedad y muestra la asimetría en la composición del capital de los sujetos y muestra, una vez más que, tal como afirmaba Marx, lo económico es determinante en última instancia.

Es en la lucha que se da al interior del campo entre ortodoxos y herejes, donde se juega la posibilidad de una conducción alterna del proceso en juego o de consolidación del grupo dominante. Esta pugna es expresada en los siguiente términos por Bourdieu: "el habitus específico, que se impone a los recién llegados como un derecho de entrada, no es más que un modo de pensamiento específico (un eîdos), principio de una elaboración específica de la realidad, basada en la creencia pre-reflexiva en el valor indiscutido de los instrumentos de elaboración y los objetos elaborados de ese modo (un éthos) (lo que el recién llegado tiene que adquirir con el juego no es el habitus que se exige tácita o explícitamente en él, sino un habitus compatible en la práctica, tanto como sea posible, y, sobre todo, moldeable y susceptible de ser convertido en habitus conforme o, en pocas palabras, congruente y dócil, es decir, abierto a la posibilidad de una reestructuración" (Bourdieu 1999:133). Este derecho de entrada es impuesto por el grupo dominante a cada nuevo ingresante y es un modo de preservar el status quo: si nada cambia siguen dominando, esto es, imponiendo visiones legitimas acerca de lo que investigar es.

La afirmación precedente señala un camino que probablemente es más factible de ser recorrido por los recién llegados al campo (en el sentido que da Bourdieu a este concepto) o por aquellos que no tienen un recorrido extenso en el mismo: al no tener tan estructurado su habitus o carecer de él directamente, las posibilidades de que pronto recuperen otros elementos que permitan operar con mayor comodidad en ese contexto es más real que en otros casos, donde el peso de la tradición torna prácticamente inviable una modificación o ajuste. Sin embargo, el peso del contexto se hace presente en forma de condicionamiento al recién llegado, tal vez bajo la forma de máximas tales como: "esto se hace asi".

\section{Tamizando la lectura}

Lejos de ser una referencia a la inutilidad de estos procedimientos, aquí argumento a favor de la necesidad de un pensamiento sobre lo social que procure ser globalizador en el sentido que da Maffesoli (6) a esa expresión. Se trata de tomar en consideración no solo lo que interesa para un estudio o análisis concreto sino que tome en cuenta la diversidad de circunstancias y determinaciones que hacen de lo social, precisamente, un objeto complejo de ser pensado $\mathrm{y}$, por ende, abordado metodológicamente, especialmente atendiendo la importancia de situar la experiencia en contextos concretos: "toda mi empresa 
científica se inspira, en efecto, en la convicción de que no se puede asir la lógica más profunda del mundo social sino a condición de sumergirse en la particularidad de una realidad empírica, históricamente situada y fechada, pero para constituirla como 'caso particular posible', según las palabras de Bachelard, es decir, como un caso de figura en el universo finito de las configuraciones posibles" (Bourdieu 1997:25).

La formación referida (la que ocurre en las facultades o instituciones de primera inserción profesional) genera un habitus de investigador que, si lo que se quiere es trabajar desde otra óptica, debe ser rediscutido con el fin de valorar los límites y potencialidades que habilita: es imperioso saber si estamos preparados para sumergirnos en el mundo social jo apenas para mojarnos los pies en sus orillas!

El señalamiento de Bourdieu es más que elocuente expresión de una concepción de lo social como dinámico e inasible de una vez y para siempre: captamos (sin dar a esta expresión otro sentido que no sea el de "tomamos aquello que definimos conceptualmente") una particular configuración de lo social en un momento histórico dado y cuya articulación de componentes se realiza desde una conceptualización de tal o cual o fenómeno como conformado por tales o cuales circunstancias y/o situaciones, eventos, acontecimientos, relaciones, etc., es decir, lo social existe así para nuestra mirada teórica, de ningún modo ese es el único modo de su existencia.

Esta relativización tiene por fin expresar que el fenómeno que interesa estudiar no existe con tal o cual configuración que hay que registrar sino hasta que lo nombramos con unos u otros conceptos, en virtud de los cuales tematizamos el fenómeno con unas u otras características. Este es un argumento más que convincente para quitar poder a la idea siempre recurrente de que, en la investigación social, se trata de "registrar" hechos, como si tales estuvieran dados de un solo modo para todas las miradas teóricas que se interesen en tales o cuales fenómenos del mundo social, como si las características de los mismos fueran autónomas e independientes del contexto y fuerzas sociales allí activas. Además, de que según sea la mirada del investigador sobre los mismos diferente será también los aspectos que tomen como definitorios del mismo (7).

Para precisar más el argumento que procuro elaborar y presentar aquí: más que el empleo de tal o cual teoría o de tal o cual técnica o procedimiento, lo que define la "tonalidad cualitativa de lo social" como lo expresaba Weber, no es hablar de ella con los conceptos y categorías que puede ponernos a disposición Bourdieu (u otros autores) o la realización de entrevistas y observación, es más bien el modo de razonar sobre la existencia y modos de darse de lo social: es algo que hay que "captar" (y aquí sí captar significa "registrar lo que allí está dado") o es una construcción conceptual que tiene directa relación con el modo en que el investigador está mentando el fenómeno.

Si se prioriza la primera postura, se terminará haciendo entrevista y luego, casi por todo análisis, contando cuántas veces el entrevistado utiliza tal o cual palabra. Si la postura es la otra, la entrevista permite una aproximación al modo en que los sujetos piensan (y se piensan) en ese momento y en ese mundo (su mundo, diría Schutz) y deja abierto el camino a la interpretación de por qué es esa y no otra la visualización.

Al respecto, conviene atender que la particular pero decisiva relación entre la posición ocupada en el espacio social y las estructuras y formas del pensamiento, es de un tipo tal que los habitus generados en ella y que dan lugar a determinadas prácticas sociales, hace que aquellos adquieran tal solidez que los hace "perdurables más no inmutables", pero sí de difícil cambio: "el problema de las condiciones sociales de formación y adquisición de las estructuras generadoras de preferencias que constituyen el habitus como lo 
social incorporado, es extremadamente complejo. Por diversas razones, este proceso es relativamente irreversible: todos los estímulos y experiencias condicionantes son, en todo momento, percibidos a través de las categorías ya construidas por las experiencias previas. De ello resulta un privilegio inevitable de las experiencias originarias y, por consiguiente, una relativa cerrazón del sistema de disposiciones que constituye el habitus" (Bourdieu 1995:92). Idéntica situación es destacada por el autor en un texto posterior, cuando expresa que: "hay una inercia (o una histéresis) de los habitus que tienen una tendencia espontánea (inscrita en la biología) a perpetuar unas estructuras que corresponden a sus condiciones de producción. En consecuencia, puede ocurrir que, según el paradigma de Don Quijote, las disposiciones estén en desacuerdo con el campo y las 'expectativas colectivas' que son constitutivas de su normalidad” (Bourdieu 1999:210).

Aquí es donde comienza a quedar delineada con claridad la orientación sociológica de la investigación social: la comprensión de las prácticas sociales encuentra su razón de ser en un contexto que tal vez diste mucho de ser el actual, es decir, responden a situaciones pasadas que son conceptualizadas como similares aunque las circunstancias por las que emergen actualmente unas formas (en el sentido que Simmel da a esta expresión) sean distintas (incluso absolutamente) a la que respondía el fenómeno en otro tiempo y contexto (tal como señalamos más atrás respecto de la dialéctica entre contexto de manifestación y contexto de surgimiento o gestación de ciertas y determinadas prácticas).

Sociologizar exige historizar (como fue señalado más atrás), a menos que se asuma a la sociedad como dada de una vez y para siempre (afirmación que no encuentra asidero ni verosimilitud en el desarrollo teórico de las ciencias sociales y humanas desde hace varias décadas). Si esta es la premisa de la intervención sociológica, entonces cualquier "captación" pensada como quien saca agua de un pozo -y cuya traducción al lenguaje sociológico clásico, presente en manuales como los citados más atrás, sería: "registro de los hechos/datos sociales"- es reducida al absurdo. Tal la expresión de Bourdieu, si hay una verdad, es que la verdad es objeto de lucha. Asumir esta premisa como fundamento de lo social supone pensar las relaciones de poder que se articulan y los particulares proyectos que se construyen a partir de la predominancia de unas u otras.

En el esfuerzo por valorar y comprender el estado de situación actual, no debe perderse de vista que la toma de conciencia de una situación socialmente determinada no alcanza para modificar los habitus generados en ella. Esto es agudamente apreciado por Bourdieu cuando señala: "también es efecto de la ilusión escolástica describir la resistencia a la dominación en el lenguaje de la conciencia -como lo hace la tradición marxista, y también esas teóricas feministas que, dejándose llevar por los habitos de pensamiento, esperan que la liberación política surja del efecto automático de la 'toma de conciencia'- ignorando, a falta de una teoría disposicional de las prácticas, la extraordinaria inercia que resulta de la inscripción de las estructuras sociales en los cuerpos. Si bien la explicación puede ayudar, sólo una auténtica labor de contraadiestramiento, que implique la repetición de los ejercicios, puede, como el entrenamiento del atleta, transformar duraderamente los habitus" (Bourdieu 1999:226-227).

Concluyendo, la estructura de disposiciones que modelan a un investigador en formación puede ser puesta en discusión a partir de un trabajo sostenido de recapacitación y esfuerzo por llevarlo a otros caminos en los modos de pensar lo social. En este caso como en el de uno con más recorrido en el campo, es necesario que se (re)conozcan las premisas desde dónde se está pensando: es preciso definir el propio espacio de acción si lo que se busca es ampliarlo y/o reorientarlo, y este es un cambio en el proceder que va desde el pensamiento hasta la práctica. No alcanza con estar al tanto de las últimas teorías de la complejidad y otras 
por el estilo, si luego intervenimos como si “lo social” estuviera allí fuera, esperándonos.

\section{Notas}

(1) Esta afirmación coincide casi plenamente con Hempel: "Las ciencias empíricas (...) pretenden explorar, describir, explicar y predecir los acontecimientos que tienen lugar en el mundo en que vivimos. Sus enunciados, por tanto, deben confrontarse con los hechos de nuestra experiencia, y sólo son aceptables si están convenientemente apoyados en una base empírica. Este apoyo empírico se consigue de muchas maneras diferentes: mediante la experimentación, mediante la observación sistemática, mediante entrevistas o estudios, pruebas psicológicas o clínicas, mediante el examen cuidadoso de documentos, inscripciones, monedas, restos arqueológicos, etc., esta dependencia de una base empírica distingue a la ciencias empíricas de las disciplinas no empíricas, la lógica y la matemática pura, cuyas proposiciones se demuestran sin referencia esencial a los datos empíricos" (1966:13). Una objeción que podría hacerse aquí es a la referencia de que "sus enunciados deben confrontarse con los hechos de nuestra experiencia" pues, justamente, los hechos que serán tomados en cuenta dependerán del tipo de enunciados que se hagan y de los supuestos sobre lo que el sujeto y la sociedad sean, es decir, no existen hechos puros, dados, siempre estos dependen de la conceptualización previa sobre su ontología. De todos modos, la afirmación de Hempel tiene razonabilidad viniendo de alguien que toma como referencia a las ciencias naturales. La cuestión se complica cuando estos mismos postulados son transferidos más o menos acríticamente a las ciencias sociales.

(2) Dice Hempel: "cabe la posibilidad de que lo que se nos exija en esa primera fase de la investigación científica sea reunir todos los hechos relevantes. Pero ¿̇elevantes con respecto a qué? (...) supongamos que la investigación se refiere a un problema específico, ¿es que no empezaríamos, en ese caso, haciendo acopio de todos los hechos -o, mejor, de todos los datos disponibles- que sean relevantes para ese problema?" (Hempel 1966: 28). Nuevamente aquí falta la referencia a que la relevancia no está dada de antemano, sino a partir de la definición que del fenómeno y su estructura y vínculos se haga desde la teoría: no son lo mismo de relevantes los hechos que mira un psicólogo conductista que los que miraría uno inspirado en la teoría piagetiana.

(3) Esto es lo que destaca Bourdieu cuando expresa que "dado que tienden a reproducir las regularidades inmanentes a las condiciones en las que ha sido producido su principio generador (...) las prácticas no se pueden deducir de las condiciones presentes que pueden parecer haberlas suscitado ni de las condiciones pasadas que han producido el habitus, principio duradero de su producción. Sólo es posible explicarlas, pues, si se relacionan las condiciones sociales en las que se ha constituido el habitus que las ha engendrado, y las condiciones sociales en las que se manifiestan: es decir, si se relacionan, mediante el trabajo científico, estos dos estados de lo social, relación que el habitus efectúa ocultándola en y por la práctica" (1995:97).

(4) Al respecto, expresa el autor: "la oposición tradicional entre los métodos llamados cuantitativos, como la encuesta por cuestionario, y los llamados cualitativos, como la entrevista, enmascara lo que tienen en común: el hecho de basarse en interacciones sociales que se cumplen bajo la coacción de estructuras sociales. Los defensores de ambas categorías metodológicas ignoran esas estructuras, cosa que también hacen, por otra parte, los etnometodólogos, propensos, a causa de su visión subjetivista del mundo social, a desconocer el efecto que las estructuras objetivas ejercen no sólo en las interacciones (entre los médicos y enfermeras, por ejemplo) que registran y analizan, sino también en su propia interacción con las personas sometidas a la observación o al interrogatorio" (Bourdieu 2002:528).

(5) Estos pueden definirse como: "estructuras estructuradas, principios generadores de prácticas distintas y distintivas -lo que el obrero come y sobre todo su manera de comerlo, el deporte que práctica y su manera de practicarlo, sus opiniones políticas y su manera de expresarlas difieren sistemáticamente del consumo o de las actividades correspondientes del industrial-, estructuras estructuradas, los habitus son también estructuras estructurantes, esquemas clasificatorios, principios de clasificación, principios de visión y de división, de gustos diferentes. Producen diferencias diferentes, operan distinciones entre lo que es bueno y lo que es malo, entre lo que está bien y lo que está mal, entre lo que es distinguido y lo que es vulgar, etc. (...) pero lo esencial es que, cuando ellas son percibidas a través de sus categorías sociales de percepción, de 
sus principios de visión y división, las diferencias en las prácticas, los bienes poseídos, las opiniones expresadas se vuelven diferencias simbólicas y constituyen un verdadero lenguaje" (Bourdieu 1997:33-34).

(6) Dice Maffesoli: "Para emplear una expresión de R. Brown, para describir una aproximación opuesta al determinismo, nosotros no estamos opuestos a cierto 'romanticismo', procediendo por intuicionismo (...) Quizás sería necesario reivindicar este nombre de sociología 'romántica' aunque dándole un sentido más amplio id est, una postura que piensa en términos de globalidad, que rechaza la discriminación, la evaluación entre lo que sería importante, significativo, y lo que no lo sería; rechaza la separación que constituye el substrato de la crítica desde el Siglo XVIII. En consecuencia, el sociólogo, 'el que ordena el mundo' no tiene por qué abstraerse, él forma parte de lo que describe, está en su interior, puede tener, por lo tanto, una visión desde adentro, una 'intuición' (...)" (Maffesoli 1991:625-626).

(7) Situación que fue claramente indicada por Hempel: “un conjunto de 'hechos' empíricos se puede analizar y clasificar de muy diversos modos, la mayoría de los cuales no serían de ninguna utilidad para una determinada investigación" (1966:30). Prestando la debida atención a que este autor escribe pensando y trabajando en el campo de las ciencias naturales y también al empleo del término "hecho" que él realiza.

\section{Bibliografía}

Andrade, L. 2005. Sociología de la desertificación. Buenos Aires: Miño y Dávila.

Andrade, L. (ed.) 2006. Lo social: inquieto (e inquietante) objeto. Aportes para pensar e intervenir. Buenos Aires: Miño y Dávila.

Andrade, L. 2007. Del tema al objeto de investigación en la propuesta epistemológica de Hugo Zemelman. Cinta moebio 30: 262-282.

Bachelard, G. 1999. La formación del espíritu científico. Contribución a un psicoanálisis del conocimiento objetivo. México: Siglo XXI.

Berger, P. y Luckmann, T. 1986. La construcción social de la realidad. Buenos Aires: Amorrortu.

Borsotti, C. 2007. Temas de metodología de la investigación en ciencias sociales empíricas. Buenos Aires: Miño y Dávila.

Bourdieu, P., Chamboredon, J. y Passeron, J. 1973. El oficio de sociólogo. México: Siglo XXI.

Bourdieu, P. y Saint Martin, M. 1989. La noblesse d’État. Grandes écoles et esprit de corps. Paris: Minuit.

Bourdieu, P. 1995. Respuestas. Por una antropología reflexiva. México: Grijalbo.

Bourdieu, P. 1996. Cosas dichas. Barcelona: Gedisa.

Bourdieu, P. 1997. Capital cultural, escuela y espacio social. México: Siglo XXI.

Bourdieu, P. 1999. Meditaciones pascalianas. Barcelona: Anagrama.

Bourdieu, P. 2002. La miseria del mundo. Buenos Aires: FCE.

Bourdieu, P. y Wacquant, L. 2005. Una invitación a la sociología reflexiva. Buenos Aires: Siglo XXI.

Durkheim, E. 1985. Las reglas del método sociológico. Buenos Aires: La Pleyade. 
Festinger, L. y Katz, D. 1993. Los métodos de investigación en las ciencias sociales. México: Paidós.

Galtung, J. 1966. Teoría y método de la investigación social. Buenos Aires: EUDEBA.

Hempel, C. 1966. Filosofía de la ciencia natural. Madrid: Alianza Universidad.

King, G., Keohane, R. y Verba, S. 2000. El diseño de la investigación social: La inferencia científica en los estudios cuantitativos. Madrid: Alianza Editorial.

Kosic, K. 1967. Dialéctica de lo concreto. Estudio sobre los problemas del hombre y del mundo. México: Grijalbo.

Maffesoli, M. 1991. La sociología de lo cotidiano dentro del marco de las sociologías francesas. Estudios Sociológicos (9)27: 623-631.

Morin, E. 2000. Introducción al pensamiento complejo. Barcelona: Gedisa.

Padua, J. 2000. Técnicas de investigación aplicadas a las ciencias sociales. México: FCE.

Piaget, J. et. al. 1973. Tendencias de la investigación en las ciencias sociales. Madrid: Alianza Universidad.

Sautu, R. 2003. Todo es teoría. Objetivos y métodos de investigación. Buenos Aires: Lumiere.

Schuster, F. (ed) 2002. Filosofía y métodos de las ciencias sociales. Buenos Aires: Manantial.

Sierra Bravo, R. 1988. Técnicas de investigación social. Teoría y ejercicios. Madrid: Paraninfo.

Sorokin, P. 1993. Respuestas a mis críticos. Los problemas de la medición en sociología. En: Romano, M. (ed). La investigación social. Buenos Aires: CEAL, pp. 111-121.

Recibido el 2 Mar 2010

Aceptado el 10 Oct 2010 